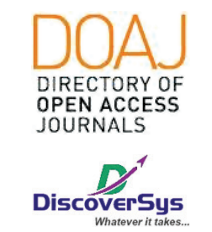

Published by DiscoverSys

\section{Deteksi dini skoliosis di tingkat Sekolah Dasar Katolik Santo Yoseph 2}

\author{
Cok Gde Prema Kurnia Baswara, ${ }^{1 *}$ I Wayan Weta, ${ }^{2}$ Luh Seri Ani ${ }^{2}$
}

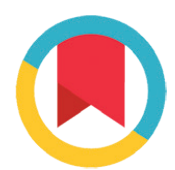

CrossMark

\title{
ABSTRACT
}

Introduction: The number of cases of scoliosis found in the world is high reach $4.5 \%$ of the total world general population, while for Indonesia and Bali there has been no incidence rate for the scoliosis. The most common case of scoliosis found is idiopathic as much as $80 \%$ of the total cases found so far. Early detection of this scoliosis plays a role to know early on whether there are abnormalities in the spine or not and if there is can to be prevented from getting worse.

Method: This study is an observational descriptive study by directly measuring the spine of elementary school students by using a scoliometer.
Result: Total of 96 primary school students who met the inclusion and exclusion criteria, the most sexes were women with 51 students (53.1\%), who were suspected of having scoliosis were 62 (64.4\%), on adolecent suspected of scoliosis with 39 students (81,3\%) and scoliosis criteria was mostly found in intermediate criteria of 55 students (88,7\%)

Conclusion: The prevalence of scoliosis in primary school students is $88 \%$, most scoliosis criteria are found at the intermediate level, and female sex is more likely to have scoliosis than men

Keywords: scoliosis, scoliometer,idiopathic

Cite the Article: Baswara, C.G.P.K., Weta, I.W., Ani, L.S. 2019. Deteksi dini skoliosis di tingkat Sekolah Dasar Katolik Santo Yoseph 2. Intisari Sains Medis 10(2): 253-257. D0I: 10.15562/ism.v10i2.185

\section{ABSTRAK}

Latar Belakang: Jumlah kasus skoliosis yang di temukan di dunia cukup tinggi mencapai angka 4,5\% dari total populasi umum dunia saat ini,sedangkan untuk di Indonesia dan Bali belum terdapat angka kejadian untuk skoliosis tersebut. Kasus skoliosis ini paling banyak ditemukan merupakan idiopatik sebanyak $80 \%$ dari total kasus yang ditemukan selama ini. Deteksi dini pada skoliosis ini berperan agar mengetahui sejak dini apakah adanya kelainan pada tulang belakang atau tidak dan jika ada agar dapat dicegah supaya tidak menjadi tambah parah.

Metode: Penelitian ini merupakan penelitian deskriptif observasional dengan mengukur langsung tulang belakang siswa sekolah dasar dengan menggunakan skoliometer.
Hasil: Dari 96 siswa sekolah dasar yang memenuhi kriteria inklusi dan eksklusi, didapatkan jenis kelamin terbanyak yaitu perempuan dengan jumlah 51 siswa $(53,1 \%)$, yang diduga menderita skoliosis didapatkan sebanyak 62 siswa $(64,4 \%)$, rentang usia adolecent paling banyak ditemukan siswa yang diduga skoliosis dengan 39 siswa (81,3\%) dan kriteria skoliosis paling banyak ditemukan pada kriteria intermediate sebanyak 55 siswa $(88,7 \%)$

Simpulan: Prevalensi skoliosis pada siswa sekolah dasar adalah $88 \%$, kriteria scoliosis terbanyak ditemukan pada level intermediate, dan jenis kelamin perempuan cenderung lebih banyak mengalami scoliosis dibandingkan dengan laki-laki.
'Program Studi Pendidikan Dokter, Fakultas Kedokteran, Universitas Udayana

${ }^{2}$ Departemen Kesehatan Masyarakat dan Kedokteran Pencegahan, Fakultas Kedokteran Universitas Udayana

${ }^{*}$ Correspondence to: Cok Gde Prema Kurnia Baswara, Program Studi Pendidikan Dokter, Fakultas Kedokteran, Universitas Udayana

codebaswara@gmail.com

Diterima: 23-03-2018

Disetujui: 04-04-2018

Diterbitkan: 01-08-2019

\section{Kata kunci: skoliosis,skoliometer,idiopatik}

Cite Pasal Ini: Baswara, C.G.P.K., Weta, I.W., Ani, L.S. 2019. Deteksi dini skoliosis di tingkat Sekolah Dasar Katolik Santo Yoseph 2. Intisari Sains Medis 10(2): 253-257. D0I: 10.15562/ism.v10i2.185

\section{PENDAHULUAN}

Skoliosis merupakan kelainan tulang belakang dimana tulang belakang mengalami pembengkokan ke arah samping (lateral curvature) membentuk huruf 'S' atau 'C' dan dapat dilihat ketika kelengkungannya semakin parah serta mengakibatkan ketidaknyamanan. ${ }^{1}$ Data yang dihimpun dari The National Scoliosis Foundation USA melaporkan bahwa kasus skoliosis ditemukan pada 4,5\% populasi umum didunia saat ini. ${ }^{2}$ Namun, di Indonesia dan di Bali kasus skoliosis belum memiliki angka pasti.

\section{Penyebab skoliosisi secara umum}

adalah kongenital (sejak dalam kandungan), penyakit neuromuscular, dan idiopatik. Sekitar $80 \%$ skoliosis adalah idiopatik dimana penyebabnya tidak diketahui. Pada skoliosis idiopatik berdasarkan rentangan kelompok umur dapat dikelompokan menjadi empat yaitu infatile (0-3 tahun), juvenile 
(4-9 tahun), adolescent (10 tahun sampai masa pertumbuhan berhenti), dan adult (>19 tahun).

Dikatakan skoliosis bila kebengkokan tulang belakang > 10 derajat dan mengenai 2-3\% anak serta tersering pada remaja, $90 \%$ pada perempuan. Menurut derajat kebengkokan (sudut Cobb) skoliosis tersebut dapat dibagi menjadi tiga yaitu ringan (10-25 derajat), sedang (25-40

derajat) dan berat ( $>40$ derajat) dengan memiliki ciri-ciri yang berbeda. Skoliosis ringan memiliki ciri: leher, bahu, pinggang terlihat tidak sama tinggi, dan baju terlihat tidak simetris. Pada skoliosis sedang, salah satu tulang belikat terlihat lebih menonjol dan sering ditemukan "rib hump" dan mudah lelah setelah aktivitas fisik. Skoliosis berat menimbulkan keluhan mudah lelah termasuk pada saat duduk atau berdiri lama, kadang kadang disertai batuk dan sesak.

Skoliosis dapat berdampak bagi penderitanya karena umumnya akan mengalami kelainan bentuk tulang belakang yang dapat menyebabkan penderita terkesan malu untuk berada di lingkungan sosial, mengalami nyeri, dan juga dapat terkena penyakit jantung dan paru-paru seperti asma. Hal ini terjadi apabila skoliosis sudah mencapai lebih dari 60 derajat sehingga menyebabkan jantung dan paru-paru terdesak oleh tulang belakang. ${ }^{3}$

\section{Deteksi dini skoliosis merupakan hal yang penting untuk mencegah}

progresivitas kebengkokanya tulang belakang sehingga penanganannya dapat lebih awal diberikan. Namun, sampai saat ini, upaya yang sudah dilakukan dalam pencegahan skoliosis hanya sebatas pemeriksaan disekolah-sekolah, khususnya pada sekolah dasar. Akan tetapi, tidak

disertai dengan upaya pencegahan primer skoliosis tersebut seperti sosialisasi tentang skoliosis dan dampak buruknya.

Skoliosis sendiri banyak dipengaruhi oleh faktor risiko yang dapat menyebabkan kondisi menjadi semakin buruk, seperti proses pertumbuhan, jenis kelamin, usia, lokasi, dan masalah tulang belakang sejak lahir.

Penyebab yang paling sering dapat mengakibatkan skoliosis adalah kebiasan kita sehari-hari dalam melakukan kegiatan tiap harinya seperti contohnya posisi duduk dan juga beban yang kita bawa tas kita.Posisi duduk dapat mempengaruhi terjadinya skoliosis karena dengan kita duduk di kursi tetapi posisi kita itu tidak tegak dan agak miring ke kanan atau ke kiri itu mengakibatkan tulang belakang kita akan di bebankan pada salah satu titik saja tidak seperti seharusnya,sama halnya dengan penggunaan tas yang membawa beban yang terlalu berat,dengan beban yang terlalu berat akibatnya bisa mendorong tubuh anak ke belakang untuk mngimbangi hal tersebut anak perlu menumpu kedepan atau kesamping ini dapat mengakibatkan skoliosis itu sendiri dan juga dapat merasakan sakit pada leher,bahu dan juga punggung

Melalui hasil pengamatan ternyata masih banyak siswa yang dapat terkena skoliosis ini dikarenakan masih banyaknya

siswa dituntut membawa banyak buku pelajaran pada saat kesekolah sehari-hari,mereka juga terhitung duduk dengan rentang waktu yang cukup lama yang dapat menyebabkan kerusakan pada tulang belakang itu sendiri

\section{METODE PENELITIAN}

Penelitian ini menggunakan desain penelitian deskriptif dengan pendekatan observasional cross-sectional (potong lintang) yang dilakukan di Sekolah Dasar Katolik Santo Yoseph 2 Kecamatan Denpasar Barat, Bali. Penelitian dilakukan pada bulan Agustus 2017 hingga Oktober 2017. Jumlah subyek dalam penelitian ini adalah sebanyak 96 orang. Adapun kriteria inklusi adalah siswa Sekolah Dasar Katolik Santo Yoseph 2 dan berada di kelas 3 dan 6, sedangkan kriteria eksklusinya adalah subyek yang pernah memiliki riwayat operasi tulang belakang, trauma pada tulang belakang, memiliki penyakit distrofi otot, dan memiliki penyakit polio.

Pemilihan sampel menggunakan teknik cluster random sampling dimana sampel akan diambil beberapa sekolah dasar yang ada di kecamatan Denpasar Barat. Pemilihan sekolah dasar berdasarkan pemilihan acak dengan menggunakan kerangka sampling daftar sekolah dasar yang berada pada kecamatan Denpasar Barat yang diperoleh dari dinas pendidikan provinsi Bali. Setiap sekolah dasar yang

terpilih akan dilakukan pemeriksaan pada seluruh siswa kelas 3 dan 6 yang memenuhi kriteria inklusi dan tidak memenuhi kriteria eksklusi.

Variabel yang akan digunakan dalam penelitian ini adalah skoliosis, posisi duduk, beban, usia, jenis kelamin dan lokasi, dimana peneliti akan mengamati postur tulang belakang subyek penelitian dan membandingankan dengan checklist mengenai kelainan tulang belakang lalu mencatat hasil penelitian sesuai yang telah diamati.

Data yang didapatkan selama penelitian akan diolah dengan program Software Microsoft Excel version 2007 (Windows) dan dari hasil pengolahan tersebut akan di sajikan dalam bentuk narasi serta tabel.

Penelitian ini telah memenuhi persyaratan dan persetujuan dari Komisi Etik Litbang Fakultas Kedokteran Udayana dengan nomor 2017.01.1.0904. 


\section{HASIL}

\section{Karakteristik Subjek berdasarkan Jenis Kelamin dan Rentang Usia}

Berikut merupakan tabel distribusi frekuensi siswa sekolah dasar yang mengikuti pengambilan data yang termasuk dalam kriteria inklusi dan eksklusi pada saat penelitian berlangsung (Tabel 1).

Berdasarkan tabel diatas didapatkan bahwa pada penelitian ini jenis kelamin perempuan memiliki jumlah sample terbanyak pada 2 rentang umur yang berbeda dengan masing-masing pada juvenile memiliki frekuensi 25 orang (52\%) dan pada adolescent memiliki frekuensi 26 orang $(54,2 \%)$ dengan total keseluruhan sample berjumlah 96 orang.

\section{Karakteristik Subjek berdasarkan Kejadian Skoliosis dan Derajat Skoliosis}

Berikut merupakan tabel distribusi frekuensi berdasarkan kejadian skoliosis dan derajat skoliosis yang sudah diukur pada subjek penelitian (Tabel 2).
Pada tabel diatas, terdapat jumlah kejadian yang dicurigai skoliosis sebesar $62(64,4 \%)$ dan tidak skoliosis sebesar 34

$(35,4 \%)$. Kemudian, dari $62(64,6 \%)$ subjek yang dicurigai skoliosis ditemukan bahwa terdapat kriteria intermediate sebanyak 55 orang siswa $(88,7)$ dan high risk sebesar 7 (11,3\%).

\section{Kejadian Skoliosis berdasarkan Jenis Kelamin dan Rentang Usia}

Data mengenai jenis kelamin serta rentang usia kemudian ditabulasikan dan dibandingkan dengan kejadian skoliosis. Berikut merupakan tabel tabulasi silang frekuensi kejadian skoliosis dengan jenis kelamin dan kelas pada subjek penelitian. (Tabel 3).

Pada tabel diatas dapat dilihat bahwa dari 62 orang siswa yang diukur,didapatkan yang di curigai skoliosis paling banyak berada di rentang umur adolescent berjumlah 39 siswa dan paling banyak ditemukan pada siswa yang berjenis kelamin perempuan pada 2 rentang umur tersebut

Tabel 1 Karakteristik Subjek berdasarkan Jenis Kelamin dan Rentang Usia

\begin{tabular}{|c|c|c|c|c|c|c|}
\hline \multirow[b]{3}{*}{ Jenis Kelamin } & \multicolumn{4}{|c|}{ Rentang Usia } & & \\
\hline & \multicolumn{2}{|c|}{$\begin{array}{c}\text { Juvenile } \\
\text { (8-9 tahun) }\end{array}$} & \multicolumn{2}{|c|}{$\begin{array}{c}\text { Adolescent } \\
\text { (10-12 tahun) }\end{array}$} & \multicolumn{2}{|c|}{ Total } \\
\hline & $\mathbf{n}$ & $\%$ & $\mathbf{n}$ & $\%$ & $\mathbf{N}$ & $\%$ \\
\hline Laki-Laki & 23 & 48 & 22 & 45,8 & 45 & 46,9 \\
\hline Perem-puan & 25 & 52 & 26 & 54,2 & 51 & 53,1 \\
\hline Total & 48 & 100 & 48 & 100 & 96 & 100 \\
\hline
\end{tabular}

Tabel 2 Karakteristik Subjek berdasarkan Kejadian Skoliosis dan Derajat Skoliosis

\begin{tabular}{lcc}
\hline Variabel & N & Frekuensi (\%) \\
\hline Kejadian Skoliosis (N=96) & & \\
$\quad$ Ya & 62 & 64,6 \\
$\quad$ Tidak & 34 & 35,4 \\
Derajat Skoliosis (N=62) & & \\
$\quad$ Intermediate & 55 & 88,7 \\
$\quad$ High risk & 7 & 11,3 \\
\hline
\end{tabular}

Tabel 3 Tabulasi Silang Frekuensi Kejadian Skoliosis dengan Jenis Kelamin dan Rentang Usia

\begin{tabular}{|c|c|c|c|c|c|c|}
\hline \multirow[b]{4}{*}{ Jenis Kelamin } & \multicolumn{4}{|c|}{ Diduga Skoliosis } & & \\
\hline & \multicolumn{4}{|c|}{ Rentang Usia } & & \\
\hline & \multicolumn{2}{|c|}{$\begin{array}{l}\text { Juvenile } \\
\text { (8-9 tahun) }\end{array}$} & \multicolumn{2}{|c|}{$\begin{array}{c}\text { Adolescent } \\
\text { (10-12 tahun) }\end{array}$} & \multicolumn{2}{|c|}{ Total } \\
\hline & $\mathbf{n}$ & $\%$ & $\mathbf{n}$ & $\%$ & $\mathbf{N}$ & $\%$ \\
\hline Laki-Laki & 10 & 43,4 & 18 & 46,2 & 28 & 45,2 \\
\hline Perem-puan & 13 & 56,6 & 21 & 53,8 & 34 & 54,8 \\
\hline Total & 23 & 100 & 39 & 100 & 62 & 100 \\
\hline
\end{tabular}


Tabel 4 Tabulasi Silang Frekuensi Derajat Skoliosis dengan Jenis Kelamin dan Kelas

\begin{tabular}{|c|c|c|c|c|c|c|c|c|}
\hline \multirow[b]{4}{*}{ Jenis Kelamin } & \multicolumn{6}{|c|}{ Diduga Skoliosis } & & \\
\hline & \multicolumn{4}{|c|}{ Intermediate } & \multicolumn{2}{|c|}{ High risk } & & \\
\hline & \multicolumn{2}{|c|}{$\begin{array}{c}\text { Juvenile } \\
\text { (8-9 tahun) }\end{array}$} & \multicolumn{2}{|c|}{$\begin{array}{c}\text { Adolescent } \\
\text { (10-12 tahun) }\end{array}$} & \multirow{2}{*}{$\frac{\begin{array}{c}\text { Juvenile } \\
\text { (8-9 tahun) }\end{array}}{\text { n }}$} & \multirow{2}{*}{$\begin{array}{c}\begin{array}{c}\text { Adolescent } \\
(10-12 \text { tahun) }\end{array} \\
\%\end{array}$} & \multicolumn{2}{|c|}{ Total } \\
\hline & $\mathbf{n}$ & $\%$ & $\mathbf{n}$ & $\%$ & & & $\mathbf{N}$ & $\%$ \\
\hline Laki-Laki & 9 & 40,9 & 15 & 45,5 & 1 & 100 & 3 & 50 \\
\hline Perempuan & 13 & 59,1 & 18 & 54,5 & 0 & 0 & 3 & 50 \\
\hline Total & 22 & 100 & 33 & 100 & 1 & 100 & 6 & 100 \\
\hline
\end{tabular}

\section{Derajat Skoliosis berdasarkan Jenis Kelamin dan Rentang Usia}

Berikut merupakan tabel tabulasi silang frekuensi derajat skoliosis dengan jenis kelamin dan kelas pada subjek yang telah dilakukan pemeriksaan (Tabel 4).

Berdasarkan tabel 4 dapat dilihat pada kriteria skoliosis intermediate paling banyak ditemukan pada jenis kelamin perempuan di kedua rentang umur juvenile $13(59,1 \%)$ siswa dan adolescent $18(54,5 \%)$ siswa, sebaliknya pada kriteria skoliosis high risk ditemukan hanya 1 kasus pada rentang umur juvenile terdapat pada siswa yang berjenis kelamin laki-laki dan pada rentang umur adolescent ditemukan sama berjumlah 3 siswa pada laki-laki maupun perempuan

\section{PEMBAHASAN}

Dalam penelitian ini dilakukan pemeriksaan pada tulang belakang untuk mengetahui apakah adanya siswa yang dicurigai menderita skoliosis, skoliosis secara umum merupakan adanya kelainan pada tulang belakang dimana tulang belakang menjadi miring ke kiri atau ke kanan. Pada penelian ini ditemukan bahwa didapatkan dari total sample 96 orang

siswa, $(64,4 \%)$ siswa dicurigai menderita skoliosis serta dari $(64,4 \%)$ siswa ini didapatkan $(88,7 \%)$ siswa masuk dalam kategori intermediate dan $(11,3 \%)$ masuk dalam kategori high risk. Menurut penelitian yang dilakukan Sengkey, L. S. (2016) didapatkan bahwa dari total kasus ditemukan $76 \%$ yang masuk dalam kategori intermediate dan hanya $4 \%$ yang masuk dalam kategori high risk.

Pada penelitian ini ditemukan bahwa yang dicurigai skoliosis berjumlah 62 orang siswa, didapatkan paling banyak pada yang berjenis kelamin perempuan dengan $(54,8 \%)$ dibandingkan dengan yang berjenis kelamin laki-laki (45,2\%), hal ini juga ditemukan pada penelitian yang dilakukan oleh Kamtsiuris (2007) diperoleh bahwa pada perempuan memiliki ratio yang lebih tinggi dibandingkan dengan laki-laki dikatakan rasio perempuan:laki-laki 1,5:1. ${ }^{4}$ Beberapa hasil studi lainnya ditemukan

\section{perempuan lebih banyak yang menderita skoliosis dibandingkan dengan laki-laki.}

Pada penelitian ini ditemukan juga bahwa yang dicurigai menderita skoliosis ditemukan pada rentang usia adolescent adanya peningkatan penemuan kasus dibandingkan dengan rentang usia juvenile hal ini sejalan dengan beberapa literature lainnya yang menyebutkan bahwa adanya peningkatan kejadian skoliosis sejalan dengan peningkatan dari umur itu sendiri.

Pada penelitian ini banyak ditemukan skoliosis yang masuk dalam kriteria intermediate pada perempuan dikedua rentang umur jika dibandingkan dengan laki-laki, perempuan pada rentang umur juvenile didapatkan 13 siswa dan pada laki didapatkan hanya 9 siswa sedangkan pada rentang umur adolescent yang berjenis kelamin perempuan diperoleh 18 siswa dibandingkan dengan laki-laki yang diperoleh 15 siswa, sesuai yang sudah dijelaskan diatas bahwa perempuan memiliki kemungkinan menderita skoliosis dibandingkan dengan laki-laki tetapi berbeda dengan yang ditemukan pada kategori high risk, pada kategori ini didapatkan pada laki-laki 4 siswa dari kedua rentangan umur dan perempuan 3 orang siswa dari kedua rentangan umur hal ini serupa dengan penelitian Weijun (2012) mendapatkan derajat skoliosis high risk lebih banyak laki-laki dibandingkan dengan

perempuan karena adanya beberapa faktor lain yang mempengaruhi hal ini. ${ }^{5}$

\section{SIMPULAN}

Pada penelitian ini, dapat disimpulkan bahwa selama periode penelitian dari Agustus 2017 sampai dengan Oktober 2017 terdapat 96 siswa yang masuk kriteria inklusi dan eksklusi subyek penelitian dan didapatkan 62 orang siswa yang dicurigai menderita skoliosis dan sejumlah 55 orang masuk dalam kriteria intermediate 
Penelitian ini juga mengungkapkan bahwa didapatkan paling banyak yang dicurigai menderita skoliosis pada perempuan sebanyak 34 orang dan juga didapatkan paling banyak pada rentangan usia adolescent sebanyak 39 orang. Pada kriteria intermediate ditemukan 34 orang yang berjenis kelamin perempuan dan kriteria high risk ditemukan 4 orang yang berjenis kelamin laki-laki serta paling banyak kriteria intermediate ditemukan 33 orang direntang usia adolescent dan kriteria high risk ditemukan 6 orang direntang usia adolescent.

\section{DAFTAR PUSTAKA}

1. Jakubowski TL, Alexy EM. Does school scoliosis screening make the grade? NASN school nurse. 2014;29(5):258- 65.

2. National Scoliosis Foundation. Scoliosis Media and Community Guide. 2009.
3. Goldberg C, Moore D, Fogarty E, Dowling F. Scoliosis: A review. Paediatrics Surgery International. 2008;24(2):129-44.

4. Kamtsiuris P, Atzpodien K, Ellert U, Schlack R, Schlaud M. Prevalence of somatic diseases in German children and adolescents. Results of the German Health Interview and Examination Survey for Children and Adolescents. Bundesgesundheitsblatt - Gesundheitsforschung Gesundheitsschutz. 2007;50(5-6):686- 700.

5. Wang W, Zhu Z, Zhu F, Sun C, Wang Z, Sun X, et al. Different curve pattern and other radiographical characteristics in male and female patients with adolescent idiopathic scoliosis. Spine. 2012;37(18):1586-92.

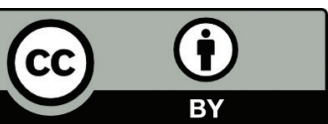

This work is licensed under a Creative Commons Attribution 